\title{
THE PSYCHOMETRIC PROPERTIES OF TURKISH VERSION OF SELF TRANSCENDENCE SCALE
}

\author{
Hakan SARIÇAM *
}

\author{
* Dumlupınar Üniversitesi E-mail: hakansaricam@gmail.com
}

Copyright (C) 2015 Hakan SARIÇAM. This is an open access article distributed under the Eurasian Academy of Sciences License, which permits unrestricted use, distribution, and reproduction in any medium, provided the original work is properly cited.

\begin{abstract}
The aim of this research is to adapt the Self- transcendence Scale (Reed, 1991) to Turkish and to examine its psychometric properties. The study has two steps. The research was conducted on 517 participants who are 167 teachers and 350 university students in Sakarya University. The validity and reliability of scale was investigated by language equality, explanatory factor analysis, confirmatory factor analysis, criterion related validity, Cronbach alpha, and test retest methods. The Meaning in Life Questionnaire and Depression, Anxiety and Stress Scale (DASS) were used for the concurrent validity. Results confirmatory factor analyses demonstrated that 15 items yielded one-factor, as original form and that the uni-dimensional model was well fit $(\chi 2 / \mathrm{df}=1.88, \mathrm{RMSEA}=.062, \mathrm{CFI}=.97, \mathrm{GFI}=.94, \mathrm{IFI}=.97, \mathrm{NFI}=.96$, $\mathrm{RFI}=.95$ and $\mathrm{SRMR}=.042$ ). Factor loadings ranged from .25 to .67. In the concurrent validity significant positive relationship was found between self-transcendence and meaning in life; negative relationships were found between self-transcendence and depression, anxiety, stress. Cronbach Alfa internal consistency coefficients were found as .87 for scale. Moreover, testretest reliability coefficient was .80 and corrected item-total correlations ranged from .34 to .56. Overall results demonstrated that Self-transcendence Scale can be used as a valid and reliable instrument; it can be used in the field of positive psychology, religion psychology and education psychology.
\end{abstract}

Keywords: Self- transcendence, validity, reliability, confirmatory factor analysis

\section{Öz Aşkınlık Ölçeği Türkçe Formunun Psikometrik Özellikleri}

\section{ÖZET}

Bu araştırmanın amacı Reed (1991) tarafından geliştirilen Öz aşkınlık Ölçeğini Türkçeye uyarlamak ve ölçeğin psikometrik özelliklerini incelemektir. Çalışma iki aşamadan oluşmaktadır. Araştırmanın katılımcılarını 167 öğretmen ve Sakarya Üniversitesi Eğitim Fakültesi'nde öğrenim gören 350 üniversite öğrencisi olmak üzere toplam 517 kişi oluşturmaktadır. Ölçeğin psikometrik özellikleri, dilsel eşdeğerlik, açıklayıcı faktör analizi, doğrulayıcı faktör analizi, ölçüt bağıntılı geçerlik, iç tutarlık ve test-tekrar test yöntemleriyle incelenmiştir. Uyum geçerliği için Yaşamın Anlamı Ölçeği ile Depresyın, Kaygı ve Stres Ölçeği kullanılmıştır. Ölçeğin yapı geçerliği için uygulanan açıklayıcı faktör analizi sonucu maddeler orijinal formla uygun olarak tek boyutta toplanmıştır. Daha sonar yapılan doğrulayıcı faktör analizi sonucu 15 maddenin tek boyuttaki uyum indeksi değerleri $(\chi 2 / \mathrm{sd}=1.76, \mathrm{RMSEA}=.062, \mathrm{CFI}=.97, \mathrm{GFI}=.94, \mathrm{IFI}=.97, \mathrm{NFI}=.96, \mathrm{RFI}=.95$ ve $\mathrm{SRMR}=$ .042) olarak bulunmuştur. Ölçeğin faktör yükleri .35 ile .57 arasında sıralanmaktadır. Ölçüt 
geçerliği çalışmasında öz-aşkınlık ile yaşam anlamı arasında pozitif ilişki, depresyon, anksiyete ve stres ile negatif ilişkiler olduğu görülmüştür. Cronbach Alfa iç tutarlılık güvenirlik katsayısı .87; test-tekrar test korelasyon katsayıs1 .80 olarak bulunmuştur. Ayrıca düzeltilmiş madde-toplam korelasyonlarının .34 ile .57 arasında sıralandığı görülmüştür. $\mathrm{Bu}$ sonuçlara göre ölçeğin pozitif psikoloji, din psikolojisi ve eğitim psikolojisinde kullanılabilecek geçerli ve güvenilir bir ölçme aracı olduğu söylenebilir.

Anahtar Kelimeler: Öz-aşkınlık, geçerlik, güvenirlik, doğrulayıcı faktör analizi

\section{GİRIŞ}

Aşkınlık kavramı yüzyıllardır din ve felsefede büyük bir yer kaplayan; bu disiplinlerdeki alan araştırmacıları arasında özellikle Tanrı-âlem ilişkisinde aşkınlık-içkinliik ikilemiyle sıkça tartışmalara konu olmuş güncelliğini hala koruyan kavramlardan biridir. "Spinoza'ya göre, var olan her şey, ya kendisinde, ya da başka bir şeyde vardir; Kendisinde var olan, kendi kendisinin nedeni olacaktır, yani onun özü, zorunlu olarak varlığını kuşatacaktır. Başka bir şey sayesinde var olan ise var-değil diye tasarlanabilendir, yani bu şeyin özü varliğını kuşatmıyor demektir. Bu ifadelerden de anlaşılacă̆ ile var olan ve etkinliği yalnı kendisi ile gerektirilmiş bulunan ve özü varllğı kuşatan, başka deyişle tabiatı ancak varolarak tasarlanabilecek olan şeye ve kendi kendisinin nedeni olan, mutlak olarak sonsuz bir varlı̆̆a, yani sonsuz sıfatları olup başslz ve sonsuz (ezelî-ebedî) özü bu sonsuz slfatlarından her biriyle ifade edilmiş olan cevhere Spinoza, Tanrl demektedir" (Arıcan, 2006). Buradan hareketle "Tanrı aşkındır" denilebilir. Varlık felsefesinde aşkınlık, deney dünyasını aşan, özce ondan ayrı olan anlamına gelmektedir (Meydan Larousse, 1990). Tanrı dışında olan varlıklar, Spinoza'ya göre Tanrı'nın tezahürü olan, tavır, mümkün, sonlu, tikel, tekil, zorunsuz ve yaratılmıs varlıklar diye de isimlendirilen varlıklardır. Dolayısıyla âlem de bu şekilde isimlendirilen varlıklardan biridir (Beşler, 2009) ve içkindir. Felsefede içkinlik, öznenin ereklerin, öznenin kendi içinde bulunması; parçası olduğu şeyi etkileyen nedenin özelliğidir. Özellikle ortaçağ felsefesinde Tanr1-âlem çerçevesinde Tanrı'ya atfedilen aşkınlık kavramı farklı disiplinlerde de kullanılmaya başlanmıştır. Örneğin, Epistemolojide aşkınlık kavramı, insan aklının kendi iç durumunun sınırlarını aşıp, kendi dışındaki gerçekliği anlama, bilme yetisi (Termbank, 2012) olarak tanımlanmıştır. Sanat ve edebiyat alanında aşkınlık: Görülen, bilinen, yaşanılan, deneyimsel dünyanın ötesine geçerek, ya da deyiş yerindeyse üstüne çıkarak bir çeşit aşkın bir dünyayla buluşmanın ruh haliyle yazılmış sanatedebiyat eserlerini nitelemek için kullanılan bir terimdir. Sanatçının kendini aşma durumudur. İyi sanat eserleri, çoğu zaman 'alıcı'sına da, bu aşkınlığı yaşatır. Transandantal felsefede ise aşkınlık, özellikle dini düşünce akımları arasında bir düşünce biçimi olarak belirmiş ve bilinen dünyanın dışında var olan tanrısal gücün dünya üzerindeki etkisinin ifadesinde çokça kullanılmıştır (Sarıçam, 2013). Bir diğer ifadeyle aşkın düşünce; dünyaya bir nevi dünya dışından bakabilme yetisi olarak da düşünülebilir. Din ve felsefe alanında bu kadar geniş bir yelpazeye sahip aşkınlık kavramı Victor Frankl'ın (1963) öz-aşkınlık kavramıyla psikoloji terminolojisinde yerini almış ve son 20 yıl içinde pozitif psikolojinin sıkça incelediği kavramlar arasına girmiştir.

Frankl (2006) öz-aşkınlığı, kişinin kendiyle meşgul olmayı bırakıp kendini başkalarına, işine, bir davaya veya başka bir etkinliğe adayabilme yetisi için kullanır. Frankl'ın öz-aşkınlık ile ilgili belki de en önemli tespiti varoluşun ve anlam arayışının öz-aşkınlık ile zirveye ulaşmasıdır. Maslow'a göre insan kendini gerçekleştirme ile hayatın anlamına ulaşırken; Frankl öz-aşkınlığı kendini gerçekleştirmekten daha üst bir değer olarak ele alır. 
Coward'a (1996) göre öz aşkınlık, kendi ötesine ulaşma ve keşfetme potansiyeli veya tavır ve bakış açısını genişleterek deneyimleri anlamlandırma kapasitesidir (Sarıçam, 2013). Öz aşkınlık maneviyatın bir göstergesi olarak ruhani kabul, doğa ile özdeşim ve kendinden vazgeçme deneyimlerini de içeren gelişimsel bir yapıdır. Hatta Reed'e (1991b) göre gelişimsel olgunluğun bir karakteristiğidir. Reed'in Öz Aşkınlık Teorisinde, öz aşkınlık: a) Kendi iç sınırlarını aşma (bir felsefenin, bir değerin bir hayalin farkına varmanın ötesinde bir olgu), b) Kişilerarası yaşama (bir çevre ve başkalarıyla ilişkili olma), c) Zamansal düşünme (geçmiş ile gelecek gidişatında şimdiyi anlamaya uyum sağlamak), d) İnsanüstü düşünme (tipik olarak görülebilen dünyanın ötesinde boyutlara ulaşmak) kapasitesi olarak geçmektedir (Sarıçam, 2013).

Frankl'a göre kişinin kendini unutabilmesi, kendi dışındaki şeylerle meş.gul olabilmesi, ruh sağlığı ve devamlılığı için temel bir önem taşır. Yapılan araştırmalarda, öz-aşkınlığın depresyon (Steven, 1999; Suzuki, 1999), ölüm anksiyetesi (Lehto ve Stein, 2009), psikolojik iyi oluş (Reed, 2008; Hoshi, 2008), hayat doyumu (Upchurch, 1999; Mellors, Riley ve Erlen, 1997) ve kırılganlık (Hoshi, 2008) ile ilişkisi olduğu vurgulanmaktadır. Bu tip önemli psikolojik kavramlarla ilişkisi bulunan, transandantal psikoloji ve logo terapide geniş bir yere sahip öz-aşkınlıkla ilgili Japon ve Amerikan literatüründe birçok çalışma ve kitap bulunmasına rağmen ülkemizde bu tür çalışmaların eksikliği, öz-aşkınlığın düzeyinin değerlendirilmesine yönelik bir ölçme aracının ülkemiz alan yazınına kazandırılması bu çalışmanın yapılmasına nedeni olmuştur. Reed (1991a) tarafından geliştirilen Öz Aşkınlık Ölçeğinin orijinal formunun yapı geçerliği için uygulanmış açıklayıcı faktör analizinde KMO örneklem uygunluk katsayısının anlamlı olduğu, tek faktörde toplanan maddelerin toplam varyansın \%80' açıklandığı görülmüştür. Fakat yap1 geçerliliği için yapılan diğer bir açıklayıcı faktör analizinde ölçek maddelerinin 2 faktörde toplandığı ve bu iki faktörün toplam varyansın \%35.3'ünü açıkladığı bulunmuştur. Ayrıca ölçeğin Cronbach Alfa iç tutarlılık güvenirlik katsayısı .80 ile 88 arasında değişmektedir. Bu çalışmanın amacı Reed (1991a) tarafından geliştirilen Öz Aşkınlık Ölçeğini ülkemiz kültürüne uyarlamak ve ölçeğin psikometrik özelliklerini incelemektir.

\section{ILK ÇALIŞMA \\ 2.1. YÖNTEM}

\subsection{1. Çalışma Grubu}

Çalışmanın ilk aşamasının çalışma grubunu 167 (91 kadın, 76 erkek) öğretmen oluşturmaktadır. Öğretmenler farklı branşlarda olup yaşları 25 ile 51 arasında değişmektedir. Öğretmenlerin yaş ortalamaları 33.8 olarak bulunmuştur.

\subsection{2. İşlem}

Öncelikle Öz Aşkınlık Ölçeğinin uyarlama çalışması için ölçeği geliştiren Pamela G. REED ile e-mail yoluyla iletişim kurulmuş ve ölçeğin uyarlanabileceğine ilişkin gerekli izin alınmıştır. Türkçeye çevrilme süreci belli aşamalardan oluşmaktadır. Öncelikle ölçek İngiliz Dili ve Edebiyatı ve Filoloji bölümü mezunu 5 dil uzmanı tarafından Türkçeye çevrilmiş ve daha sonra bu Türkçe formlar tekrar İngilizceye çevrilerek her iki dili bilen 23 kişiye uygulama yapılarak bu iki form arasındaki tutarlılık incelenmiştir. Yine aynı öğretim üyeleri elde ettikleri Türkçe formlar üzerinde tartışarak anlam ve gramer açısından gerekli düzeltmeleri yapmış ve denemelik Türkçe form elde edilmiştir. Son aşamada bu form, psikolojik danışma ve rehberlik ve ölçme ve değerlendirme alanındaki 3 öğretim üyesine inceletilerek görüşleri doğrultusunda bazı değişiklikler yapıldıktan sonra bir uygulama formu oluşturulup katılımcılara uygulanmıştır. Elde edilen veriler bilgisayar ortamına aktarıldıktan 
sonra SPSS 17 paket programı aracıllı̆̆ıyla maddelere açıklayıcı faktör analizi (AFA) yapılmıştır.

\subsection{BULGULAR VE YORUM}

\subsubsection{Dilsel Eşdeğerlik}

İngilizce ve Türkçeyi çok iyi bilen 23 kişiye iki hafta arayla yapılan uygulamada Türkçe ve İngilizce formlar arasında .93 ilişki bulunmuştur.

\subsubsection{Yapı geçerliği}

Ölçeğin yapı geçerliği için ilk çalışmada 167 öğretmenden elde edilen verilerin faktör analizine uygunluğunu tespit etmek amaciyla Kaiser-Meyer-Olkin (KMO) katsayıs1 hesaplanmış ve Barlett Spehericity testi yapılmıştır. Verilerin faktör analizine uygunluğu için KMO .60'dan yüksek ve Barlett testinin anlamlı çıkması gerekmektedir (Büyüköztürk, Akgün, Kahveci, \& Demirel, 2004). Yapılan analiz sonucu KMO örneklem uygunluk katsayıs1 .75, Bartlett Sphericity testi $\chi^{2}$ değeri $1199.603(\mathrm{p}<.001, \mathrm{sd}=105)$ bulunmuştur. Ölçeğin yetişkinlerden oluşan çalışma grubunda faktör yapısını ortaya koymak üzere açıklayıcı faktör analizi (AFA) yapılmıştır. AFA yapılırken ölçeğin orijinali ile uyumlu tek faktörlü bir yapı elde etmek amaçlandığı için, temel bileşenler tekniği ile oblik döndürme faktör çözümlemesi sonuçları tek faktörle sınırlandırılmıştır. Analiz sonucunda toplam varyansın \%57.58' ini açıklayan tek faktörlü bir yapı elde edilmiş ve sonuçlar Tablo 1.de verilmiştir.. Bu bulgulara göre ölçeğin madde faktör yapısının Türk kültürüne uygun olduğu, fakat maddelerin doğrulanması gerektiği sonucuna ulaşılmıştır.

Tablo 1. AFA faktör yükleri ve varyans değeri

\begin{tabular}{cccc}
\hline Madde & $\begin{array}{c}\text { Faktör } \\
\text { yükleri }\end{array}$ & Madde & $\begin{array}{c}\text { Faktör } \\
\text { yükleri }\end{array}$ \\
\hline $\mathbf{1}$ & .57 & $\mathbf{9}$ & .51 \\
$\mathbf{2}$ & .52 & $\mathbf{1 0}$ & .45 \\
$\mathbf{3}$ & .51 & $\mathbf{1 1}$ & .45 \\
$\mathbf{4}$ & .56 & $\mathbf{1 2}$ & .45 \\
$\mathbf{5}$ & .57 & $\mathbf{1 3}$ & .34 \\
$\mathbf{6}$ & .46 & $\mathbf{1 4}$ & .52 \\
$\mathbf{7}$ & .45 & $\mathbf{1 5}$ & .48 \\
$\mathbf{8}$ & .53 & \multicolumn{2}{c}{$\mathbf{\% 5 7 . 5 8}$} \\
\hline
\end{tabular}

\section{3. İKINCI ÇALIŞMA}

\subsection{YÖNTEM}

\subsection{1. Çalışma Grubu}

Çalışmanın ikinci aşaması 350 (202 kadın, 148 erkek) üniversite öğrencisinin katılımıyla gerçekleştirilmiştir. Öğrencilerin 45'i fen bilgisi öğretmenliği, 67'ü okul öncesi öğretmenliği, 131'i psikolojik danışmanlık ve rehberlik, 55'i sınıf öğretmenliği ve 52'si sosyal bilgiler 
öğretmenliği bölümlerinde öğrenim görmektedir. Katılımcılar 17 ile 27 yaş arasında olup ve yaş ortalaması 20.8 olarak hesaplanmıştır.

\subsubsection{Veri Toplama Araçları}

Yaşamın Anlamı Ölçeği: Yaşamın anlamı ölçeği, insanların yaşamda buldukları ve aradıkları anlamı belirlemek amacıyla Steger, Frazier, Oishi ve Kaler (2006) tarafindan geliştirilmiştir. Yaşamın Anlamı Ölçeği 7'li Likert (1 kesinlikle geçerli değil-7 kesinlikle geçerli) tipi bir ölçme aracıdır ve 10 maddeden oluşmaktadır. Madde sayısı 10 olan ölçek, "anlamın varlığı" ve "anlam arayışı" olmak üzere iki alt boyuttan oluşmaktadır. Doğrulayıcı faktör analizi sonucu uyum indeksi değerleri $\left(\chi^{2} / \mathrm{sd}=1.86, \mathrm{RMSEA}=.054, \mathrm{GFI}=.96, \mathrm{AGFI}=.93, \mathrm{IFI}=.98\right.$, $\mathrm{CFI}=.98, \mathrm{RMR}=.052$ ) olarak bulunmuştur. Ölçeğin uyarlanmasına ilişkin güvenirlik analizlerinde iç tutarlık katsayısı .86 olarak bulunmuştur. Test tekrar test güvenirliği için yapılan iki uygulama sonucu arasındaki ilişki ise .81 olarak hesaplanmıştır. Geçerlik çalışması için yapılan temel bileşenler analizinde ölçeğin orijinalindeki iki boyutlu yapıyı koruduğu görülmüştür. Doğrulayıcı faktör analizinde ise faktör yükleri .70 ile .84 arasında değişen istatistiksel olarak anlamlı değerler elde edilmiştir

Depresyon Anksiyete Stres Ölçeği (DASS-42): Lovibond ve Lovibond (1995) tarafından geliştirilen ölçeğin Türkçe formunun geçerlik ve güvenirlik çalışması Bilgel ve Bayram (2007) tarafından yapılmıştır. 42 maddeden oluşan ölçeğin 14 maddesi depresyon, 14 maddesi kaygı ve 14 maddesi stres faktörleri altında yer almakta olup "0" bana hiç uygun değil, "1" bana biraz uygun, "2" bana genellikle uygun ve "3" bana tamamen uygun şeklinde puanlanmaktadır. Doğrulayıcı faktör analizi sonucu uyum indeksi değerleri $\left(\chi^{2} / \mathrm{sd}=3.17\right.$, $\mathrm{RMSEA}=.04, \mathrm{GFI}=.90, \mathrm{CFI}=.92, \mathrm{RMR}=.052)$ olarak bulunmuştur. DASS-42'nin Cronbach Alpha iç tutarlılık katsayıları ölçeğin bütünü için .89, depresyon, anksiyete ve stres alt boyutları için sırasıyla $.92, .86$ ve .88 olarak bulunmuştur. Düzeltilmiş madde toplam korelasyonları .33 ile .70 arasında siralanmaktadır.

\subsection{3. İşlem}

Bu aşamada Öz-aşkınlık ölçeğinin Türkçe formu, Yaşam Anlamı ve Depresyon, Anksiyete, Stres Ölçekleri birleştirilerek 350 üniversite öğrencisine uygulanmıştır. Elde edilen veriler bilgisayar ortamına aktarıldıktan sonra SPSS 17 ve LISREL 8.54 paket programı aracılığıyla öz aşkınlık ölçeğinin maddelerine doğrulayıcı faktör analizi (DFA) yapılmıştır. Uyum indeks değerlerini genel kabul edilen AGFI, GFI, CFI, IFI, NFI, RFI ve IFI için > .90, RMSEA ve SRMR için < 05 ölçüt olarak alınmıştır (Hu ve Bentler,1999; Jöroskog, ve Sörbom, 1996; Tabachnick ve Fidell, 2007). Ölçüt geçerliği çalışması için toplam puan ortalamaları üzerinden korelasyon katsayısını tespit etmek için Pearson momentler korelasyon analizi uygulanmiştır.

\subsection{BULGULAR VE YORUM}

\subsubsection{Geçerlik}

Yapı geçerliği. Ölçeğin yapı geçerliği için 350 üniversite öğrencisinden elde edilen verilere tek boyutlu model için uygulanan doğrulayıcı faktör analizinde uyum indeksi değerleri: $\chi^{2}=$ $151.39, \mathrm{sd}=86\left(\chi^{2} / \mathrm{sd}=1.76\right), \mathrm{RMSEA}=.062, \mathrm{CFI}=.97, \mathrm{GFI}=.94, \mathrm{IFI}=.97, \mathrm{NFI}=.96, \mathrm{RFI}=$ $.95, \mathrm{SRMR}=.042$ olarak bulunmuştur. Ölçeğin faktör yükleri .35 ile .57 arasında sıralanmakta olup sonuçlar Şekil 1'de verilmiştir. 
Şekil 1. Öz-aşkinlık Ölçeğinin maddelerine ilişskin Path diyagramı

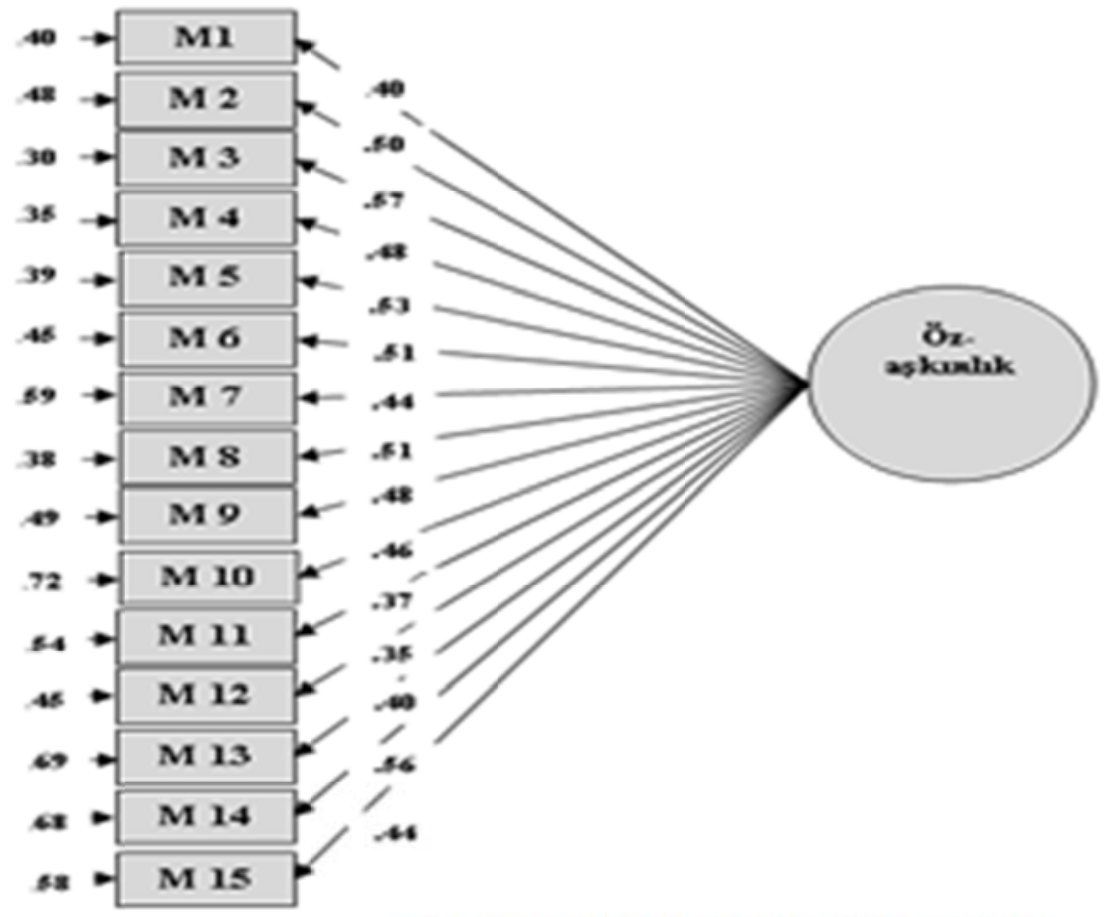

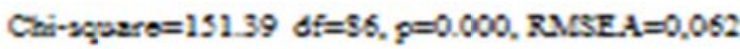

Uyum geçerliği. Ölçeğin uyum geçerliği çalışmasında 350 kişilik çalışma grubu içinde depresyondan şikayeti olan 109 öğrenciden elde edilen verilere uygulanan Pearson Momentler Çarpımı korelasyon analizi sonucu, öz aşkınlık ile mevcut anlam ve aranan anlam arasında sırasıyla $(r=.51, .19)$ pozitif ilişki; öz aşkınlık ile depresyon, kaygı ve stres arasında sırasıyla $(r=-.39,-.38,-.36)$ negatif ilişki bulunmuş; sonuçlar Tablo 2.'de verilmiştir.

Tablo 2. Değişkenlerin açıklayıcı bilgileri, ortalamalar, standart sapma ve korelasyon değerleri

\begin{tabular}{lcccccc}
\hline Değişkenler & 1 & 2 & 3 & 4 & 5 & 6 \\
\hline 1. Mevcut anlam & - & & & & & \\
2. Aranan anlam & $.24^{* *}$ & - & & & & \\
& & & & & & \\
3. Depresyon & $-.43^{* *}$ & $.29^{*}$ & - & & & \\
& & & & & & \\
4. Kayg1 & $-.27^{* *}$ & $.26^{* *}$ & $.57^{* *}$ & - & & - \\
& & & & & & \\
5. Stress & $-.23^{* *}$ & $.30^{* *}$ & $.60^{* *}$ & $.51^{* *}$ & - & \\
6. Öz-aşkınlık & $.51^{* *}$ & $.19^{*}$ & $-.39^{* *}$ & $-.38^{* *}$ & $-.36^{* *}$ & - \\
$M$ & 26.26 & 19.06 & 18.87 & 13.74 & 23.09 & 49.67 \\
SD & 5.73 & 5.42 & 5.83 & 4.74 & 6.28 & 3.91 \\
Alpha & .80 & .84 & .83 & .81 & .87 & .87 \\
\hline${ }^{*} p<.05,{ }^{* *} p<.01$ & & & & & &
\end{tabular}




\subsubsection{Güvenirlik}

İç tutarlılık. Öz Aşkınlık Ölçeğinin Cronbach alfa iç tutarlılık güvenirlik katsayısı.87 olarak bulunmuştur.

Test-tekrar test. Ölçek 17 gün ara ile aynı gruptan 57 kişiye tekrar uygulanılı̆ında, iki uygulama arasındaki korelasyon katsayısı .76 olarak hesaplanmışır.

\subsubsection{Madde analizi}

Düzeltilmiş madde-toplam korelasyonu. Yapılan analiz sonucunda ölçeğin düzeltilmiş maddetoplam korelasyonları .32 ile .61 arasında sıralanmakta olup sonuçlar Tablo 3.'te verilmiştir.

Tablo 3. Düzeltilmiş madde-toplam korelasyonu değerleri

\begin{tabular}{cccc}
\hline Madde No & $\begin{array}{c}\text { Düzeltilmiş madde } \\
\text { toplam korelasyonu }\end{array}$ & Madde No & $\begin{array}{c}\text { Düzeltilmiş madde } \\
\text { toplam korelasyonu }\end{array}$ \\
\hline $\mathbf{1}$ & .60 & $\mathbf{9}$ & .54 \\
$\mathbf{2}$ & .52 & $\mathbf{1 0}$ & .33 \\
$\mathbf{3}$ & .51 & $\mathbf{1 1}$ & .34 \\
$\mathbf{4}$ & .56 & $\mathbf{1 2}$ & .33 \\
$\mathbf{5}$ & .61 & $\mathbf{1 3}$ & .32 \\
$\mathbf{6}$ & .47 & $\mathbf{1 4}$ & .52 \\
$\mathbf{7}$ & .37 & $\mathbf{1 5}$ & .36 \\
$\mathbf{8}$ & .57 & & \\
\end{tabular}

\section{TARTIŞMA VE SONUÇ}

Bu çalışmada yetişkinlerin öz-aşkınlık düzeylerini belirlemeye yönelik Öz-aşkınlık Ölçeğinin (Self-transcendence Scale) Türkçeye uyarlanması amaçlanmıştır. Bu amaç: doğrultusunda Özaşkınlık Ölçeğinin geçerliği, faktör analizi, ayırt edici geçerlik ve benzer ölçek geçerliği ile belirlenmiştir. Faktör analizi açıklayıcı faktör analizi (AFA) ve doğrulayıcı faktör analizi (DFA) şeklinde yapılmıştır. AFA uygulanmasının nedeni öz-aşkınlık Ölçeğinin orijinal formunun faktör yapısının Türk örnekleminde değerlendirmek, DFA kullanılmasının nedeni orijinal formun faktör yapısının yetişkinler üzerinde doğrulanıp doğrulanmadığını incelemektir (Büyüköztürk vd., 2004; Sümer, 2000). AFA sonucunda faktör yükleri literatürde kabul edilebilir değer olan .30' dan (Büyüköztürk, 2012; Çokluk, Şekercioğlu ve Büyüköztürk, 2012) yüksektir. DFA sonucu ise ölçeğin tek boyutlu olarak iyi uyum verdiği ve kabul edilebilir bir fit değerine sahip olduğu söylenebilir. Çünkü SRMR ile RMSEA değerinin 0,05 ve altında çıkması iyi bir fit değerini, 0,08 ve altında olması ise kabul edilebilir bir fit değerini göstermektedir (Şimşek, 2007; Tabachnick ve Fidell, 2007). Ayırt edici geçerlik çalışması sonucunda ölçekte yer alan 15 maddenin alt grupla üst grubu birbirinden anlamlı düzeyde ayırt ettiği görülmüştür. Uyum geçerliği (ölçüt geçerliği) çalışması sonucunda ise ölçeğin geçerli olduğu sonucuna varılmıştır. Öz aşkınlık Ölçeğinin güvenirlik çalışmaları sonuçlarına bakıldığında ise Cronbach-alfa iç tutarlık, madde toplam korelasyonu katsayıları ile test-tekrar test yöntemiyle elde edilen korelasyon katsayılarının kabul edilebilir 
düzeyde olduğu görülmektedir. Alanyazında Cronbach-alfa iç tutarlık güvenirlik katsayısı minimum değeri .70; düzeltilmiş madde toplam korelasyon değerlerinin .30 kriterinden büyük olması (Erkuş, 2012) Öz Aşkınlık Ölçeğinin psikolojik ölçme aracı geliştirme ve uyarlama kriterlerine uygun olduğunu göstermektedir.

Öz-aşkınlık Ölçeğinin geçerlik ve güvenirlik çalışmalarından elde edilen bulgular, Türk kültürüne uyarlanan 15 maddelik kendine değerlendirmeye yönelik olan ölçeğin yetişkinlerin öz aşkınlık düzeylerini geçerli ve güvenilir bir şekilde ölçmek amacıyla kullanılabileceğini göstermektedir. Cevaplama sistemi her ifade için "1" Hiç, "2" Çok az, "'3" Oldukça ve "4" Çok arasında 4'lü puanlama şeklindedir. Her bir maddenin puanları 1 ile 4 arasında değiştiğinden ölçekten alınabilecek en düşük puan 15, en yüksek puan ise 60'tır.

Öz-aşkınlık Ölçeğinin bireylerin aşkınlık düzeyleri ile ilgili bilgi vermesi yaşam anlamı, kendini gerçekleştirme hakkında fikir sağlamasının yanı sıra yapılacak terapilerde ve psikolojik danışma uygulamalarına da birçok kolaylık oluşturacağı düşünülmüş; ayrıca ülkemizdeki konuyla ilgili alanyazın (psikoloji, felsefe, din, eğitim) incelendiğinde böyle bir ölçeğin olmaması, bu çalışmayla birlikte alanyazının zenginleşeceği fikrini uyandırmıştır. Ölçeğin yapı geçerliliği için daha fazla sayıda katılımcı kullanarak açıklayıcı faktör analizi (AFA) yapılmalıdır. AFA uygularken temel bileşenler tekniği ile oblik döndürme yapılmadan, maddelerin kültürümüzde özgün formundaki gibi aynı alt boyutlarda toplanıp toplanamayacağı incelenebilir. Böyle yapılırsa iç tutarlılık güvenirlik katsayısı ve madde faktör yükleri ile madde toplam korelasyonları artabilir. Bu çalışmanın yetişkinlerden elde edilen verilerle yürütülmesinin nedeni, öz aşkınlığın ahlaki olgunlukla dolayısıyla yaş ile ilgili olmasından kaynaklanmaktadır. Fakat ölçeğin psikometrik özelliklerinin farklı çalışma gruplarıyla birlikte özellikle küçük yaş gruplarında incelenmesi son derece önemlidir. Son olarak, ölçeğin benlik saygısı, öz duyarlık, affedicilik, özgünlük düzeylerini belirleyen geçerli ve güvenilir ölçme araçlarıyla ilişkisine bakılabilir.

\section{REFERENCES}

- Arıcan, M. K. (2006). Spinoza'nın Tanrı-âlem ilişkisinde içkinlik aşkinlik problemi. Cumhuriyet Üniversitesi İlahiyat Fakültesi Dergisi, 10(1), 127-143.

- Beşler, P. (2009). Spinoza felsefesinde beden-bilinç bağlaminda özgürlük. Yayınlanmamış Yüksek Lisans Tezi, İstanbul Üniversitesi, İstanbul.

- Bilgel, N., \& Bayram, N. (2010). Turkish version of the Depression Anxiety Stress Scale (DASS- 42): Psychometric properties. Archives of Neuropsychiatry, 47, 118-26

- Büyüköztürk, Ş. (2012). Veri analizi el kitabı. Ankara: PegemA Yayıncılık.

- Büyüköztürk, Ş., Akgün, Ö., Kahveci, Ö., \& Demirel, F. (2004). Güdülenme ve Öğrenme Stratejileri Ölçeği’nin Türkçe formunun geçerlik ve güvenirlik çalışması. Kuram ve Uygulamada Eğitim Bilimleri, 4(2), 207-239.

- Çokluk, Ö., Şekercioğlu, G., \& Büyüköztürk, Ş. (2012). Sosyal bilimler için çok değişkenli istatistik. Ankara: PegemA Yayıncılı.

- Demirbaş, N. (2010). Yaşamda anlam ve yılmazlık. Yayınlanmamış Yüksek Lisans Tezi, Hacettepe Üniversitesi, Ankara.

- Erkuş, A. (2012). Psikolojide ölçme ve ölçek geliştirme-I. Ankara: PegemA Yayıncilik.

- Frankl, V. E. (2012). İnsanın anlam arayışı. İstanbul: Okuyan Us Yayınları

- Frankl, V. E. (2006). Man's search for ultimate meaning. Boston: Beacon Press.

- Hoshi, M. (2008). Self-transcendence, vulnerability, and well-being in hospitalized Japanese elders. Unpublished Phd Thesis, University of Arizona. 
- Hu, L. T., \& Bnetler, P. M. (1999). Cutoff criteria for fit indexes in covariance structural analysis: Conventional criteria versus new alternatives. Structural Equation Modeling, 6, 1-55.

- Meydan Larousse (1990). Meydan larousse büyük lügat ve anksilopedi. Istanbul: Sabah Yay.

- Jöroskog, K. G., \& Sörbom, D. (1996). Lisrel VI: Analysis of linear structural relationships by maximum likelihood, instrumental variables, and least squares methods. Mooresville, IN: Scientific Software.

- Lehto, R. H., \& Stein, K. F. (2009). Death Anxiety: An analysis of an evolving concept. Research and Theory for Nursing Practice: An International Journal, 23(1), 23-41.

- Levenson, M. R., Jennings, P. A., Aldwin, C. M., \& Shiraishi, R. W. (2005). Selftranscendence: conceptualization and measurement. Int'l. J. Aging and Human Development, 60(2) 127-143.

- Loy, D. (1996). Lack and transcendence: The problem of death and life in psychotherapy, existentialism and Buddhism. Amherst. NY: Prometheus Books.

- Mellors, M. P., Riley, T. A., \& Erlen, H. A. (1997). HIV, self-transcendence, and quality of life. Journal of the Association of Nurses in AIDS Care, 8(2), 59-69.

- Reed. P. G. (2008). The theory of self-transcendence. In M.J., Smith \& P. R. Liehr (Eds.), Middle Range Theory for Nursing, (pp. 145-166). New York: Springer.

- Reed, P. G. (1991a). Self-transcendence and mental health in oldest-old adults. Nursing Research, 40(1), 5-11.

- Reed, P. G. (1991b). Toward a nursing theory of self-transcendence: Deductive reformulation using developmental theories. Advances in Nursing Science, 13(4), 6477.

- Sarıçam, H. (2013). Öz-aşkınlık (Self-transcendence), İçinde Ahmet AKIN (Ed), Güncel Psikolojik Kavramlar (Benlik) (ss. 185-194). Sakarya: Sakarya Üniversitesi Eğitim Bilimleri Enstitüsü Yayınları.

- Sarıçam, H., Çardak, M., Uysal, R., Ilbay, A. B., \& Akin, A. (2012, May). Turkish version of the Short form of Resilience Appraisal Scale: The validity and reliability study. Paper presented at the International Counseling and Education Conference (ICEC 2012), May, 3-5, Istanbul, Turkey.

- Steger, M. F., Frazier, P., Oishi, S., \& Kaler, M. (2006). The Meaning in Life Questionnaire: Assessing the presence of and search for meaning in life. Journal of Counseling Psychology, 53(1), 80-93.

- Stevens, D. D. (1999). Spirituality, self-transcendence and depression in young adults with AIDS (Immune Deficiency). Dissertation Abstracts International, B61(02), (University Microfilms No. 9961253).

- Suzuki, M. (1999). The relationship of depression and self-transcendence among community-living Japanese elders. Unpublished master's thesis, University of Arizona, Tucson, Arizona.

- Sümer, N. (2000). Yapısal eşitlik modelleri: Temel kavramlar ve örnek uygulamalar. Türk Psikoloji Yazıları, 3(6), 49-74.

- Şimşek, Ö. F. (2007). Yapısal eşitlik modellemesine giriş: Temel ilkeler ve Lisrel uygulamaları. Ankara: Ekinoks Yayınları.

- Tabachnick, B. G., \& Fidell, L. S. (2007). Using multivariate statistics. Boston: Allyn and Bacon.

- Termbank (2012). http://www.termbank.net/psychology/862.html 
- Tornstam, L. (1994). Gero-transcendence: A theoretical and empirical exploration. In L. E. Thomas, \& S. A. Eisenhandler (Eds.), Aging and the religious dimension (pp. 203-225). London: Auburn House.

- Upchurch, S. (1999). Self-transcendence and activities of daily living: The woman with the pink slippers. Journal of Holistic Nursing, 17(3), 251-266

- Yılmaz, V., \& Çelik, H. E. (2009). Lisrel ile yapisal eşitlik modellemesi-I: Temel kavramlar, uygulamalar, programlama. Ankara: PegemA Yayınları. 